\title{
Inhibition of Fas associated phosphatase 1 (Fap1) facilitates apoptosis of colon cancer stem cells and enhances the effects of oxaliplatin
}

\author{
Weiqi Huang ${ }^{1}$, Ling Bei ${ }^{1,2}$ and Elizabeth A. Eklund ${ }^{1,2}$ \\ ${ }^{1}$ Feinberg School of Medicine, Northwestern University, Chicago IL, USA \\ ${ }^{2}$ Jesse Brown Veteran's Administration Medical Center, Chicago IL, USA \\ Correspondence to: Elizabeth A. Eklund, email: e-eklund@northwestern.edu \\ Keywords: stem cell; phosphatase; Fas; apoptosis; gene transcription \\ Received: February 28, $2018 \quad$ Accepted: April 28, $2018 \quad$ Published: May 25, 2018 \\ Copyright: Huang et al. This is an open-access article distributed under the terms of the Creative Commons Attribution License \\ 3.0 (CC BY 3.0), which permits unrestricted use, distribution, and reproduction in any medium, provided the original author and \\ source are credited.
}

\section{ABSTRACT}

Fas associated phosphatase 1 (Fap1) is a ubiquitously expressed protein tyrosine phosphatase. Fap1 substrates include Fas and Gsk3 $\beta$, suggesting a role in regulating cell survival. Consistent with this, increased Fap1 expression is associated with resistance to Fas or platinum induced apoptosis in some human colon cancer tumors or cell lines. In the current studies, we found that Fap1 expression was significantly greater in $\mathrm{CD}_{133^{+}}$colon cancer stem cells compared to CD133- tumor cells. PTPN13 promoter activity (encoding Fap1) was repressed by interferon regulatory factor 2 (irf2), and expression of Fap1 and Irf2 were inversely correlated in $\mathrm{CD}_{133^{+}}$or CD133- colon cancer cells. We determined that $\mathrm{CD} 133^{+}$cells were relatively resistant to Fas or oxaliplatin induced apoptosis, but this was reversed by Fap1-knockdown or a Fap1-blocking tripeptide (SLV). In a murine xenograft model of colon cancer, we found treatment with SLV peptide significantly decreased tumor growth and relative abundance of $\mathrm{CD}_{133}{ }^{+} \mathrm{CD} 44^{+}$cells; associated with increased phosphorylation of Fap1 substrates. SLV peptide also enhanced inhibitory effects of oxaliplatin on tumor growth and Fap1 substrate phosphorylation in this model. Our studies suggest that therapeutically targeting Fap1 may decrease persistence of colon cancer stem cells during treatment with platinum chemotherapy by activating Fap1 substrates. In a murine model of chronic myeloid leukemia, we previously determined that inhibition of Fap1 decreased persistence of leukemia stem cells during tyrosine kinase inhibitor treatment. Therefore, Fap1 may be a tissue agnostic target to increase apoptosis in malignant stem cells.

\section{INTRODUCTION}

Approximately $4 \%$ of individuals in the USA will be diagnosed with colorectal cancer (CRC) during their lifetime [1]. Once distant metastases develop, no current therapeutic approaches prolong survival in this disease [2]. Tumors that recur after chemotherapy or at metastatic sites are less sensitive to platinum-based chemotherapy compared to primary colon cancer tumors [3]. The mechanism for this is not known, but such tumors are hypothesized to be relatively enriched for colon cancer stem cells (CSC) compared to primary and/ or chemotherapy naïve tumors [4]. Treatment approaches specifically targeting CSCs may be beneficial for decreasing tumor recurrence or metastatic potential.

Colon cancer stem cells are identified by expression of CD133, CD44, CD26 and Lgr5, although some data suggests this profile may be modulated during metastasis, ex vivo cell manipulation, or passage in culture [5-11]. Relative quiescence of these cells is hypothesized to render them less sensitive to cell cycle-active chemotherapeutic agents such as cis-platinum or oxaliplatin [5]. Malignant 
stem cells are also hypothesized to be relatively Fas resistant. In the current studies, we hypothesize that Fas-resistance of some colon cancer stem cells is due to increased expression of Fap1; a ubiquitously expressed protein tyrosine phosphatase [12]. Fap1 expression is increased in metastatic versus primary tumors, with increasing Duke's stage, and after treatment with platinum versus in chemotherapy naive tumors [13]. However, relative Fap1 expression in various tumor cell populations has not been investigated.

Fap1 substrates include Fas and Gsk $3 \beta[14,15]$. Fap1 interacts with the Fas C-terminus through a Fap1PDZ domain; dephosphorylating Fas and inhibiting apoptosis [14]. Other investigators identified an inverse correlation between Fap1 and Fas-induced apoptosis in some colon cancer cell lines, or platinum induced apoptosis in some primary patient CRC samples $[14,16$, 17]. A tripeptide representing the Fas C-terminus (SLV) blocks the Fap1-PDZ domain and prevents interaction of Fap1 with partner proteins $[18,19]$. Consistent with this, SLV peptide restored Fas-induced apoptosis in colon cancer cell lines with increased Fap1, and cisplatin sensitivity in samples from patients with platinuminsensitive tumors [14].

We determined that interaction of Fap1 with Apc (the adenomatous polyposis coli protein) results in dephosphorylation (inactivation) of Gsk3 $\beta$ by Fap1 [19]. Since phosphorylation of $\beta$ catenin by Gsk $3 \beta$ results in $\beta$ catenin ubiquitination and proteasomal degradation, Fap1 stabilizes $\beta$ catenin through this mechanism [15]. We found that SLV peptide blocked Fas-resistance and $\beta$ catenin-activation in Fap1 overexpressing leukemia cells $[15,20]$. Fap 1 expression is increased in $\mathrm{CD} 34^{+}$leukemia stem cells (LSCs) from chronic myeloid leukemia (CML) patients and further increases upon disease progression [12]. We also found that Fap 1 contributed to persistence of CML-LSCs during tyrosine kinase inhibitor treatment; facilitating relapse [20].

We determined that transcription of the PTPN13 promoter (encoding Fap1) was repressed by Icsbp/ Irf8 (interferon consensus sequence binding protein/ interferon regulatory factor 8 ) in myeloid leukemia cells [21]. Although expression of Icsbp is myeloid restricted, other interferon regulatory factors are expressed in colon cancer cells. Specifically, Irf2 is expressed in CRC cells and polymorphisms in the $I R F 2$ gene are implicated in the pathogenesis of this disease [22].

In the current studies, we investigate the impact of Fap1 on tumor growth in a murine xenograft model of colon cancer. We also study regulation of Fap 1 expression and the relative influence of Fap1 on CRC-CSCs versus other cell populations in the tumors. Based on these results, we hypothesize Fap1 influences the biology of malignant stem cells in a tissue agnostic manner in neoplasms as diverse as CRC and CML, and might be a rationale therapeutic target to prevent relapse, and/or effect cure, in a number of cancers.

\section{RESULTS}

\section{Fap1 is increased in $\mathrm{CD} 133^{+}$colon cancer cells}

Fap1 expression inversely correlates with sensitivity to Fas-induced apoptosis in some colon cancer cell lines [23]. This includes SW480; a Fas sensitivity line with relatively low Fap1 expression that was derived from a primary colon cancer tumor [23, 24]. SW620 was derived from a metastatic lesion from the same patient, but has not been directly compared to SW480 cells for Fap1 expression or Fas-sensitivity. We found significantly more Fap1 in SW620 versus SW480 cells, consistent with increased Fap1 expression upon disease progression (Figure 1A) [13]. We performed additional studies to determine the mechanism for this difference between primary and metastatic CRC tumors.

We first investigated the possibility that increased Fap1 was a characteristic of cancer stem cells in particular, rather than metastatic tumors in general, by determining Fap1 expression in $\mathrm{CD}_{133^{+}}$populations from these lines. We found significantly more Fap1 mRNA in CD133+ cells from either line compared to the total cell population $(\mathrm{p}<0.001, \mathrm{n}=6)$ (Figure 1A). Consistent with this, Fap1 protein was more abundant in CD133-selected cells versus the total population (Figure 1B). Importantly, Fap1-expression was not significantly different in $\mathrm{CD} 133^{+}$ SW480 cells versus $\mathrm{CD} 133^{+} \mathrm{SW} 620$ cells $(\mathrm{p}=0.07, \mathrm{n}=6)$ (Figure 1A).

Since Fap1 inversely correlates with platinum sensitivity, we determined the effect of oxaliplatin on Fap1 expression. In assays with total cell populations, oxaliplatin significantly increased Fap1 mRNA in both lines, but expression was still significantly greater in SW620 versus SW480 cells $(\mathrm{p}<0.001, \mathrm{n}=6)$ (Figure 1A). However, oxaliplatin did not significantly increase Fap1 expression in the $\mathrm{CD} 133^{+}$population from SW480 or SW620 cells ( $\mathrm{p}=0.05, \mathrm{n}=6$ ) (Figure 1A). Therefore, differences in Fap1 expression in metastatic lesions versus primary CRC tumors, or pre versus post oxaliplatin, were explained by the relative abundance of $\mathrm{CD} 133^{+}$cells.

\section{Irf2 regulated PTPN13 promoter activity in colon cancer cells}

We were interested transcriptional regulation of the gene encoding Fap1 (PTPN13) in CRC cells. However, Icsbp/Irf8-expression, which regulates this gene in hematopoietic cells, is generally restricted to differentiating phagocytes or B cells [25]. Since this Icsbp/Irf8 protein shares some target genes with the ubiquitously expressed Irf2 (interferon regulatory factor 
$2)$, we investigated relative expression of the two in the CRC cell lines [26].

Irf2 was easily detected in SW480 or SW620 cells, but was significantly less abundant in the latter $(\mathrm{p}<0.01$, $\mathrm{n}=6$ comparing the lines) (Figure $1 \mathrm{C}$ ). For both lines, Irf2 mRNA abundance was significantly less in $\mathrm{CD}_{133}{ }^{+}$cells versus the total population $(\mathrm{p}<0.01, \mathrm{n}=6)$ (Figure $1 \mathrm{C}$ ). Therefore, expression of Irf2 inversely correlated with Fap1. Expression of Icsbp/Irf8 was more than a log less than Irf2 in both lines and in $\mathrm{CD}_{133^{+}}$cells (Figure 1C).

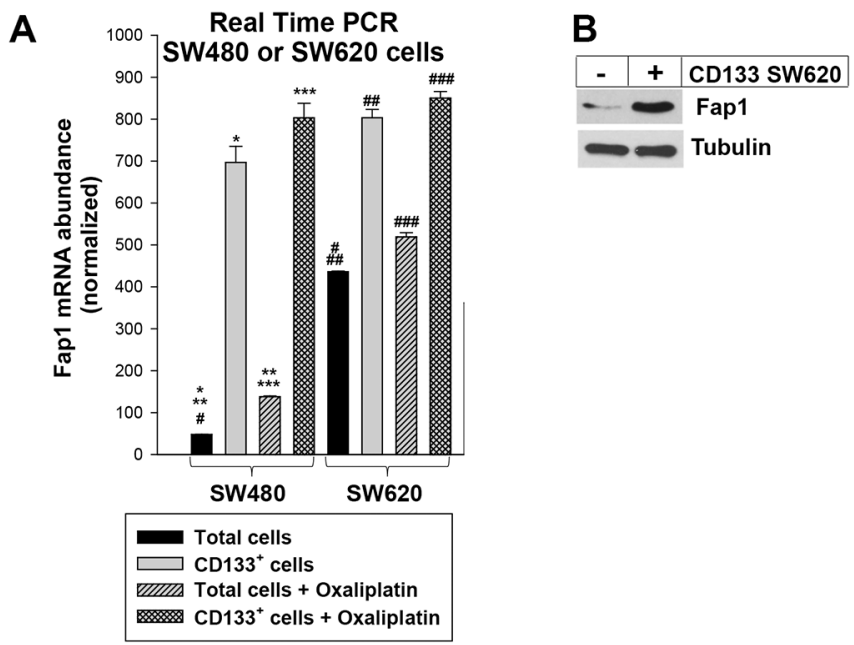

D

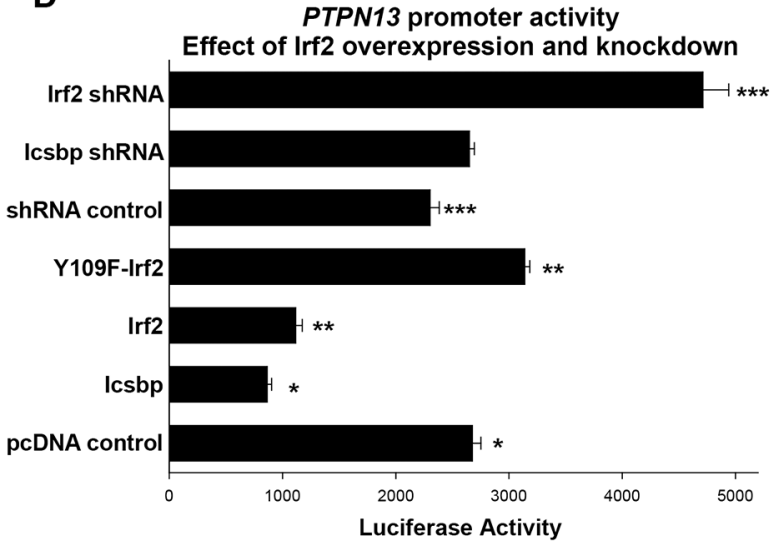

To investigate PTPN13 promoter activity, we transfected SW620 cells with a construct containing 1.0 $\mathrm{kb}$ of 5' flank linked to a luciferase reporter (or empty reporter vector) [21]. Cells were co-transfected with vectors to overexpress Icsbp, Irf2, Y109F-Irf2, or control vectors; or shRNAs specific to Icsbp or Irf2, or scrambled shRNA control vectors. We found that overexpression of either Icsbp or wild type Irf2 decreased PTPN13 promoter activity $(\mathrm{p}<0.0001, \mathrm{n}=4)$, but Y109F-Irf2 did not (Figure 1D). Phosphorylation of Y109 is required for
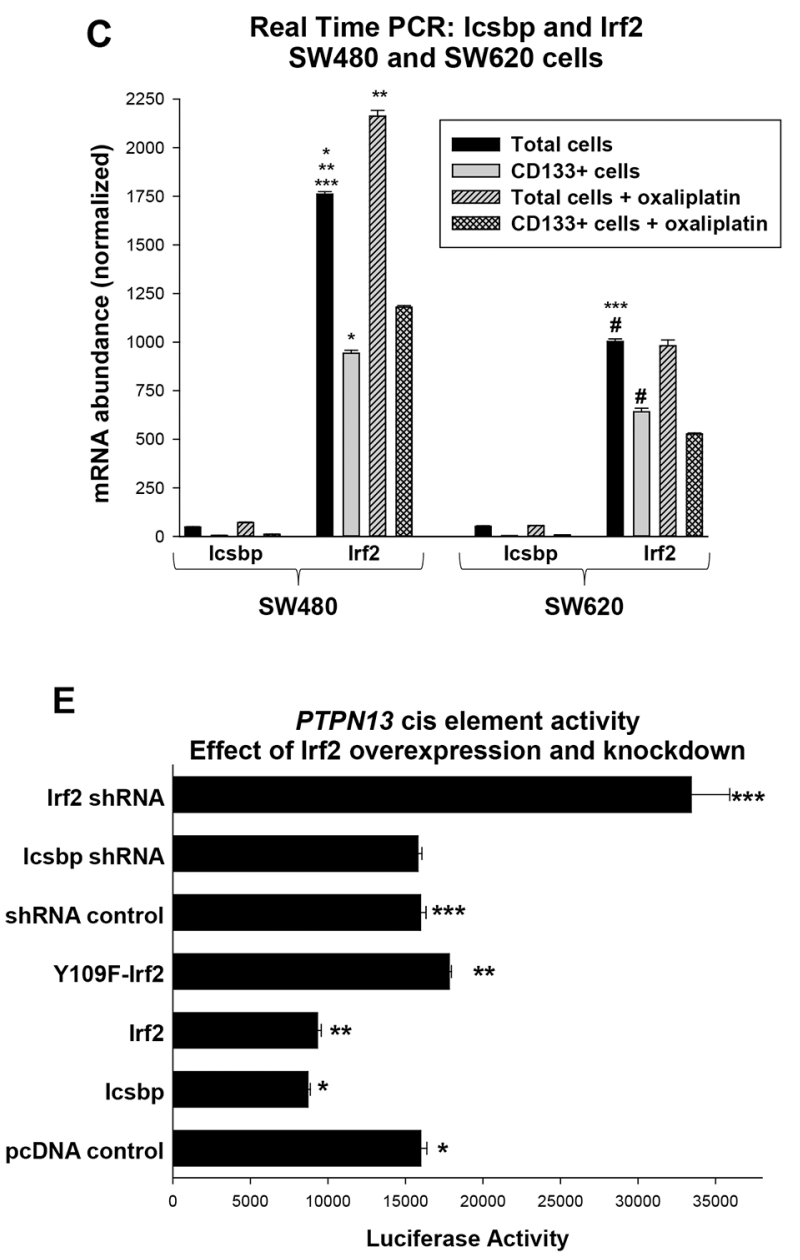

Figure 1: Fap1 expression is increased in $\mathrm{CD} 133^{+}$colon cancer cells and the PTPN13 promoter is regulated by Irf2. (A) Expression of Fap1 is correlated with $\mathrm{CD}_{133^{+}}$cell abundance in colon cancer cell lines. Total SW480 or SW620 cells, or CD133 ${ }^{+}$ cells isolated from these lines, were analyzed for Fap1 mRNA by real time PCR. Significant differences are indicated by ${ }^{*},{ }^{* *},{ }^{* * *},{ }^{\#,{ }^{*},}$, or \#\# ( $\mathrm{p}<0.01, \mathrm{n}=6$ for all comparisons). (B) Fap1 protein is more abundant in CD133 ${ }^{+}$cells vs CD133- cells. CD133 ${ }^{+}$cells that were isolated from the SW620 line were compared to CD133- cells by Western blot of total lysate proteins. Blots were probed from Fap1 and Tubulin (as a loading control). (C) Irf2 expression is decreased in CD133 $3^{+}$cells vs the total SW480 or SW620 cell population, and significantly less Icsbp is expressed in these cells compared to Irf2. Total SW480 or SW620 cells, or CD133 ${ }^{+}$cells isolated from these lines, were analyzed for Icsbp or Irf2 mRNA by real time PCR. Significant differences are indicated by ${ }^{*},{ }^{* *},{ }^{* * *}$, or ${ }^{\#}(\mathrm{p}<0.01, \mathrm{n}=6$ for all comparisons). (D) Irf2 represses the PTPN13 promoter. SW620 cells were transfected with a construct with $1.0 \mathrm{~kb}$ of PTPN13 promoter linked to a luciferase reporter and vectors to overexpress Icsbp, wild type Irf2, or Y109F-Irf2 (versus empty control vector), or to knockdown Icsbp or Irf2 (with specific shRNA versus scrambled shRNA vector). Significant differences indicated by ${ }^{*},{ }^{* *}$, or ${ }^{* * *}(\mathrm{p}<0.001, \mathrm{n}=6$ for all comparisons). (E) Irf2 represses the Icsbp-binding cis element from the PTPN13 promoter. SW620 cells were transfected with a construct with three copies of the previously identified PTPN13 cis element linked to a minimal promoter and luciferase reporter. Cells were co-transfected with vectors to overexpress or knockdown Icsbp or Irf2, as described above. Significant differences indicated by ${ }^{*},{ }^{* *}$, or ${ }^{* * *}$ ( $\mathrm{p}<0.001, \mathrm{n}=6$ for all comparisons). 
Irf2-binding to some target genes [21]. And, knockdown of Irf2 significantly increased PTPN13/reporter construct activity (versus scrambled control) $(\mathrm{p}<0.001, \mathrm{n}=4)$, but knockdown of Icsbp/Irf8 did not (consistent with low levels of expression of endogenous Icsbp in these cells, $\mathrm{p}=0.7, \mathrm{n}=4$ ) (Figure 1D). Neither overexpression nor knockdown of either protein influenced expression of control, empty reporter vector in these studies (subtracted as background). Results were normalized for transfection efficiency using a constitutively active renilla luciferase control vector.

We performed additional studies to determine if Irf2 and Icsbp influenced the same PTPN13 cis element [21]. For these studies, SW620 cells were transfected with a luciferase reporter vector with three copies of the Icsbp-binding site from the PTPN13 promoter linked to a minimal promoter (or empty minimal promoter/ reporter control vector). Cells were co-transfected with vectors to overexpress or knockdown Icsbp and Irf2 (or relevant control vectors), as described above. We found the PTPN13 cis element was equivalently repressed by overexpressed Icsbp or Irf2, but only activated by knockdown of Irf2 (Figure 1E). Neither knockdown nor overexpression of these proteins influenced activity of the empty, minimal promoter/reporter vector (subtracted as background). Cells were co-transfected with a constitutively active renilla luciferase reporter vector as an internal control for transfection efficiency.

\section{The SW620 cell line is relatively enriched for $\mathrm{CD} 133{ }^{+}$cells compared to SW480 cells}

Results of studies using total vs CD133+ cells from the SW480 and SW620 lines suggested a difference in relative abundance of colon cancer stem cells in the two lines. Specifically, these results suggested CD133 ${ }^{+}$cells were relatively more abundant in the SW620 metastatic line compared to the SW480 primary tumor line. As an initial approach to this question, we performed flow cytometry for $\mathrm{CD}_{133^{+}}$cells in the two lines (Figure 2A). Consistent with our hypothesis, we found an increase in the absolute number (Figure $2 \mathrm{~B})(\mathrm{p}<0.001, \mathrm{n}=6)$ and relative percent (Figure $2 \mathrm{C})(\mathrm{p}<0.001, \mathrm{n}=6)$ of $\mathrm{CD} 133^{+}$ cells in SW620 versus SW480 cells.

Since CSCs are hypothesized to be relatively chemotherapy resistant, we examined the effect of oxaliplatin on the total cell population and $\mathrm{CD}_{133}{ }^{+}$ subset in both lines. We found that oxaliplatin decreased the total number of SW480 or SW620 cells ( $<<0.0001$, $\mathrm{n}=6$ ) (Figure $2 \mathrm{~B}$ ), but increased the relative abundance of CD133 ${ }^{+}$cells $(\mathrm{p}<0.001, \mathrm{n}=6)$ (Figure $\left.2 \mathrm{C}\right)$. This effect was greater in SW480 versus SW620 cells ( $\sim 66 \%$ increase versus $\sim 20 \%$ increase, $\mathrm{p}<0.01, \mathrm{n}=6$ ) (Figure $1 \mathrm{C}$ ). This was consistent with a greater sensitivity of CD133- cells to oxaliplatin compared $\mathrm{CD}_{133^{+}}$cells, and a greater abundance of CD133 cells in the SW480 line.

\section{Fap1 contributed to Fas-resistance in colon cancer stem cells}

We next investigated the influence of Fap1 on Fas or platinum induced cell death in $\mathrm{CD}_{133}{ }^{+} \mathrm{CRC}$ cells. In the first set of experiments, apoptosis was determined by flow cytometry for Annexin $\mathrm{V}$ staining with versus without a Fas agonist antibody (4 independent experiments, assayed in triplicate). We found SW480 cells were significantly more sensitive to Fas-induced apoptosis than SW620 cells $(\mathrm{p}<0.001, \mathrm{n}=4)$ (Figure 3A). Treatment with Fap1blocking, SLV peptide increased the apoptotic response to the Fas agonist antibody in SW480 cells $(62.5 \% \pm 1.2 \%$ increase in apoptosis with Fas antibody in SLV treated cells versus a $37.6 \% \pm 0.8 \%$ increase with Fas antibody in VLS treated control cells; $\mathrm{p}<0.01, \mathrm{n}=4$ ) and SW620 cells $(51.1 \% \pm 1.5 \%$ increase in apoptosis with Fas antibody in SLV treated cells versus $10.0 \% \pm 0.3 \%$ increase with Fas antibody in VLS treated control cells; $\mathrm{p}<0.01, \mathrm{n}=4$ ).

Therefore, Fap1 inhibition had a relatively greater effect on Fas resistance in the metastatic, SW620 line. Since these differences might be due to $\mathrm{CD}_{133^{+}}$cell abundance in SW620 versus SW480 lines, we investigated the impact of Fap1 on Fas-resistance in these cells. CD133 ${ }^{+}$ SW620 or SW480 cells were isolated and analyzed for apoptosis with or without Fas agonist antibody, as above. Cells were treated with SLV or VLS control peptide, or transduced with vectors to express Fap1-specific shRNAs (or scrambled control).

We found CD133+ ${ }^{+}$SW620 cells were resistant to Fas-induced apoptosis, but either SLV peptide or Fap1knockdown significantly increased Fas sensitivity $(\mathrm{p}<0.001$, $\mathrm{n}=4$ comparing $\%$ apoptotic cells after Fas antibody \pm Fap 1 inhibition) (Figure 3B). Oxaliplatin significantly increased baseline apoptosis in CD133 ${ }^{+}$SW620 cells $(\mathrm{p}<0.001, \mathrm{n}=4)$, but did not increase the sensitivity of these cells to Fasagonist antibody (Figure 3B). However, the combination of oxaliplatin plus SLV peptide or Fap1 knockdown significantly increased Fas-induced apoptosis $(p<0.001$, $\mathrm{n}=4$ comparing the Fas-antibody induced apoptosis in oxaliplatin treated cells \pm Fap1-inhibition) (Figure 3B). Therefore, Fap1 inhibition increased sensitivity to Fas and oxaliplatin in CD133 ${ }^{+}$SW620 cells.

Oxaliplatin increased intrinsic apoptosis in the absence of Fap1 inhibition or Fas-induced apoptosis. Therefore, we also assayed for extrinsic apoptosis versus intrinsic apoptosis by determining cleavage of caspase 8 versus 9 , respectively (by ELISA). We found that treatment with SLV peptide resulted in a significant increase in Fas-antibody induced caspase 8 cleavage in $\mathrm{CD}_{133}{ }^{+}$SW620 cells $(\mathrm{p}<0.0001, \mathrm{n}=4)$ (Figure 3C). The addition of oxaliplatin to SLV peptide significantly increased the percent of Fas-antibody induced caspase 8 cleavage in these cells $(\mathrm{p}<0.001, \mathrm{n}=4)$. In contrast, oxaliplatin significantly increased caspase 9 cleavage in these cells $(\mathrm{p}<0.001, \mathrm{n}=4)$, but SLV peptide did not 
$(\mathrm{p}=0.2, \mathrm{n}=4)$ (Figure 3D). We also investigated the effect of oxaliplatin and Fap1-inhibition on Fas expression in control experiments. For these studies, plasma membrane proteins were isolated from $\mathrm{CD} 133^{+}$SW620 cells and analyzed by Western blot (with $\mathrm{Na}+/ \mathrm{K}+$ ATPase as a loading control). Neither treatment altered Fas expression in these cells (Figure 3E).

We performed similar studies in $\mathrm{CD} 133^{+} \mathrm{SW} 480$ cells. We found resistance to Fas and oxaliplatin induced apoptosis was equivalent in $\mathrm{CD} 133^{+} \mathrm{SW} 480$ and $\mathrm{CD} 133^{+}$ SW620 cells $(\mathrm{p}>0.1, \mathrm{n}=4)$ (Figure 3F). We also found an equivalent impact of Fap1-inhibition on $\mathrm{CD}_{133^{+}}$cells from the two lines (Figure 3F). These studies suggested CD133+ colon cancer cells from primary or metastatic tumors were equivalently resistant to oxaliplatin or Fas induced apoptosis, but this was reversed by inhibition of Fap1.

\section{Fap1 inhibition decreased growth of colon cancer xenografts and delayed relapse after oxaliplatin treatment}

To investigate the impact of Fap1 on tumor growth and oxaliplatin sensitivity in vivo, we used a murine xenograft model. For these studies, SW620 cells were injected in the flanks of athymic Nude mice. Once tumors were $>200 \mathrm{~mm}^{3}$, mice were treated by daily intraperitoneal (IP) injection of Fap1-blocking SLV peptide or VLS control peptide (12 per group). Tumors were measured twice weekly and mice with tumors $>2,000 \mathrm{~mm}^{3}$ were sacrificed.

Tumors grew significantly more slowly in mice treated with SLV peptide compared to VLS control (Figure 4A). Indeed, a significant difference in tumor size was detected by 1.5 weeks of treatment which persisted throughout the experiment $(\mathrm{p}<0.001, \mathrm{n}=12)$. In the VLS control group, no mice survived the $3^{\text {rd }}$ week of the experiment, but $80 \%$ of SLV peptide treated mice survived 6 weeks, representing a statistically significant survival improvement $(\mathrm{p}<0.001, \mathrm{n}=12)$ (Figure 4B).

Since oxaliplatin is the cornerstone of contemporary CRC treatment [26], we also examined the impact of Fap1-inhibition on relapse after treatment with this agent. For these studies, athymic Nude mice were injected with SW620 cells and treatment with SLV peptide or VLS control was initiated, as above. Cohorts were simultaneously treated with oxaliplatin (once a week

A
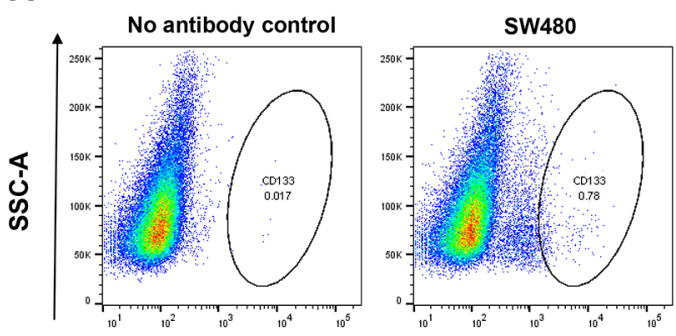

SW480 + oxaliplatin

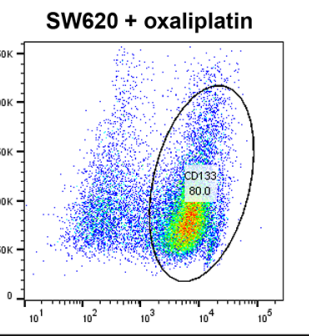

CD133

B

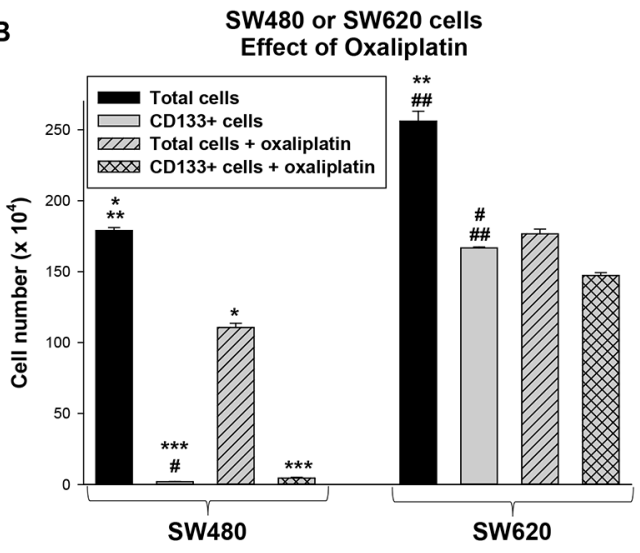

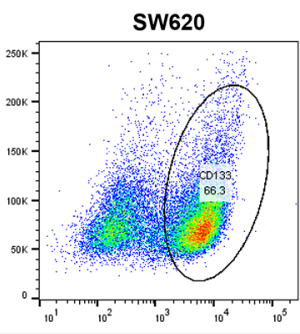
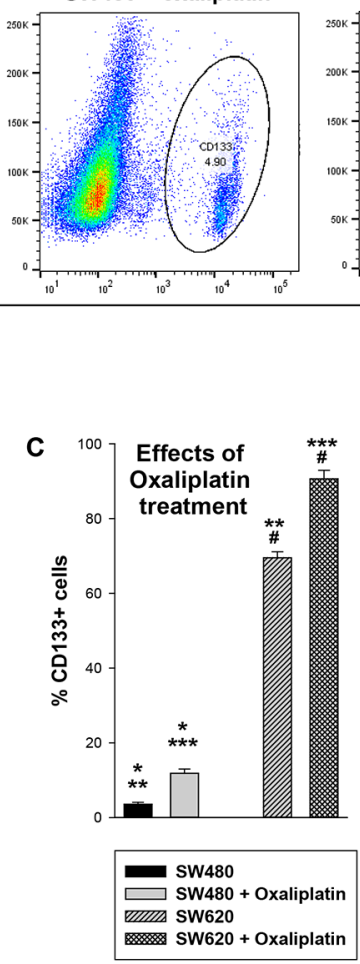

Figure 2: Treatment with oxaliplatin decreases total SW480 or SW620 cells, but increases the relative number of CD133 $^{+}$cells in these lines. (A) SW480 and SW620 cells were analyzed by flow cytometry for CD133 ${ }^{+}$cells with versus without oxaliplatin treatment. Histograms were gated using unstained cells as a control. (B) Oxaliplatin treatment decreased the total number of SW480 or SW620 cells, but the number of $\mathrm{CD} 133^{+}$cells were relatively unaffected. Absolute numbers of cells under the various conditions were determined. Statistically significant differences are indicated by ${ }^{*},{ }^{* *},{ }^{* * *},{ }^{\#}$, or ${ }^{\# \#}(\mathrm{p}<0.0001, \mathrm{n}=6$ for all comparisons). (C) The percent of $\mathrm{CD} 133^{+}$cells was determined before or after oxaliplatin treatment in both lines. Significant differences indicated by ${ }^{*},{ }^{* *},{ }^{* * *}$, or $^{*}$ $(\mathrm{p}<0.001, \mathrm{n}=6$ for all comparisons). 
for three weeks; 12 per group). Treatment with SLV or VLS peptide was continued until mice were sacrificed, according to the parameters described above.

We found that SLV peptide treatment significantly delayed tumor growth after oxaliplatin treatment in comparison to treatment with VLS control peptide $(\mathrm{p}<0.001, \mathrm{n}=12$ for later time points) (Figure 4A). Survival was significantly prolonged by oxaliplatin treatment compared to treatment with VLS control peptide alone and was prolonged in oxaliplatin treated mice by the addition of SLV peptide $(\mathrm{p}<0.001, \mathrm{n}=12)$ (Figure 4B).

We examined tumors harvested simultaneously from the treatment groups at various time points (i.e. tumors were obtained from an SLV peptide treated mouse when VLS control treated mice were sacrificed due to tumor size). Disaggregated cells were analyzed by flow cytometry for populations associated with CRC-
CSC activity; CD $133{ }^{+} \mathrm{CD}_{4}{ }^{+}$(Figure 5A). These cells represented $25.9 \% \pm 2.0 \%$ of total cells in tumor from VLS treated mice, but only $2.4 \% \pm 0.2 \%$ of total cells in tumors from SLV treated mice $(\mathrm{p}<0.001, \mathrm{n}=6)$ (Figure $5 B)$. Total CD $133^{+}$cells in tumors from VLS versus SLV treated mice were $98.2 \% \pm 2.0 \%$ versus $64.2 \% \pm 2.1 \%$, respectively $(\mathrm{p}<0.001, \mathrm{n}=6)$.

We also found the addition of SLV peptide to oxaliplatin significantly decreased relative abundance of both $\mathrm{CD}_{133^{+}}$cells $(54.1 \% \pm 1.2 \%$ versus $86.7 \% \pm$ $1.3 \%$ with versus without SLV) and $\mathrm{CD} 133^{+} \mathrm{CD} 44^{+}$cells $(1.7 \% \pm 0.2 \%$ versus $3.5 \% \pm 0.4 \%$ with versus without SLV) $(\mathrm{p}<0.001, \mathrm{n}=6)$ (Figure 5C). Relative abundance of $\mathrm{CD}_{133^{+}}$or $\mathrm{CD} 133^{+} \mathrm{CD} 44^{+}$cells was significantly less in tumors from oxaliplatin treated mice compared to mice treated with VLS or SLV peptide alone $(\mathrm{p}<0.02$, $\mathrm{n}=6$ for oxaliplatin + VLS versus VLS or SLV alone).
A
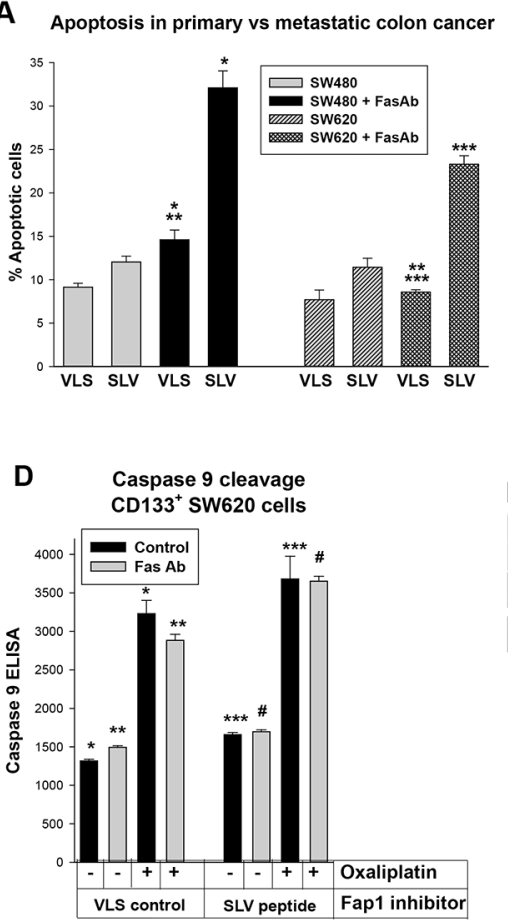
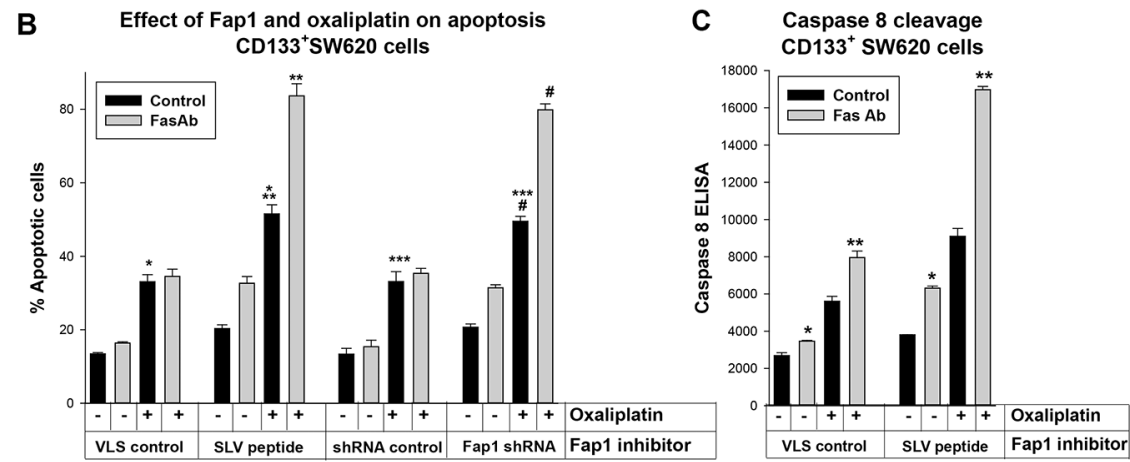

E

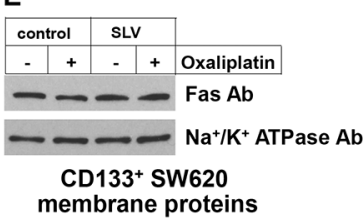

F Effect of Fap1 and oxaliplatin $\mathrm{CD}_{133^{+}} \mathrm{SW} 480$ cells

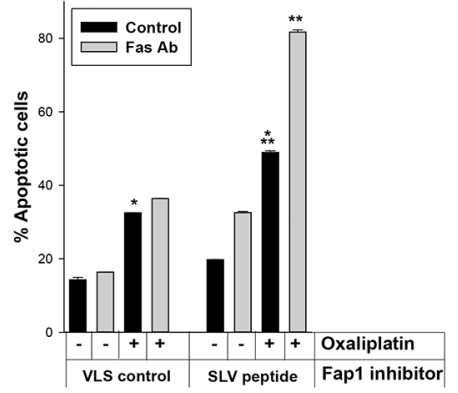

Figure 3: Fap1-inhibition increased Fas or oxaliplatin induced apoptosis in CD133+ colon cancer cells. (A) Fap1-blocking SLV peptide increases Fas-induced apoptosis. Total SW480 or SW620 cells were treated with SLV peptide (or VLS control), with or without Fas-agonist antibody, and analyzed for apoptosis by Annexin V staining. Significant differences indicated by ${ }^{*},{ }^{* *}$, or ${ }^{* * *}(\mathrm{p}<0.01$, $\mathrm{n}=4$ for all comparisons). (B) Fap1-inhibition increases Fas or oxaliplatin induced apoptosis in CD133 ${ }^{+}$SW620 cells. CD133 ${ }^{+}$SW620 cells were analyzed for apoptosis by Annexin V staining, with or without Fas-agonist antibody. Some cells were treated with SLV peptide (or VLS control) or transduced with a vector to express Fap1 specific shRNAs (or scrambled control). Significant differences indicated by ${ }^{*},{ }^{* *},{ }^{* * *}$, or ${ }^{*}\left(\mathrm{p}<0.001, \mathrm{n}=4\right.$ for all comparisons). (C) Fap1-inhibition increases Fas induced caspase 8 cleavage in CD133 ${ }^{+} \mathrm{SW620}$ cells. Cells were analyzed by ELISA for cleavage of caspase 8 (death receptor induced apoptosis). Statistically significant differences indicated by ${ }^{*}$ or ${ }^{* *}(p<0.001, n=4)$. (D) Oxaliplatin treatment increases caspase 9 cleavage in CD133 ${ }^{+}$SW620 cells. Cells were analyzed by ELISA for cleavage of caspase 9 (intrinsic apoptosis). Statistically significant differences indicated by ${ }^{*},{ }^{* *},{ }^{* * *}$, or $^{\#}(\mathrm{p}<0.001, \mathrm{n}=4)$. (E) Plasma membrane expression of Fas was not altered by SLV peptide or oxaliplatin treatment of CD133 ${ }^{+}$SW620 cells. Western blots of cell lysates were probed for Fas or $\mathrm{Na}+/ \mathrm{K}+$ ATPase (as a loading control). (F) Fap1 inhibition increases Fas or oxaliplatin induced apoptosis in CD133 ${ }^{+}$ SW480 cells. Similar experiments were performed with the SW480 cell line. Statistically significant differences are indicated by ${ }^{*}$ or $^{* *}$ $(\mathrm{p}<0.001, \mathrm{n}=6$ for both comparisons). 


\section{Fap1-inhibition increased phosphorylation of Fas and Gsk3 $\beta$ in colon cancer xenografts}

We were interested in determining the impact of Fap1-inhibition on phosphorylation of Fap1 substrates in the xenograft tumors. We initially examined the histology of tumors from mice treated with VLS, SLV, oxaliplatin + VLS, or oxaliplatin + SLV (Figure 6A). We found tumors from mice treated with oxaliplatin + VLS or VLS alone were highly disorganized (Figure 6A). However, tumors from mice treated with SLV peptide, with or without oxaliplatin, exhibited some areas of gland formation. This was consistent with the decrease in $\mathrm{CD} 133^{+}$cells in tumors from mice treated with SLV peptide, with or without oxaliplatin. We also examined these tumors for Fap1 expression (by immunofluorescent microscopy). We found that fluorescent intensity of Fap1 antibody stained cells was significantly decreased by treatment with oxaliplatin or SLV peptide $(\mathrm{p}<0.001, \mathrm{n}=6)$, but further decreased by the combination of the two $(\mathrm{p}<0.01, \mathrm{n}=6)$ (Figure 6A).

We also performed immunohistochemistry to determine expression and tyrosine phosphorylation state of Fap1 substrates. We found treatment with SLV peptide significantly increased Fas phosphorylation, but not total Fas protein (Figure 6B). This effect was further enhanced by combined treatment with SLV peptide and oxaliplatin. We found similar results in studies of phospho-Gsk3 $\beta$ (Figure 6C). Therefore, increased cell death and decreased tumor growth in mice treated with Fap1-inhibitor correlated with increased phosphorylation of Fap1 substrates in vivo.

We were interested in determining if Fap1-inhibition activated Fas or Gsk $3 \beta$ in $\mathrm{CD} 133^{+}$colon cancer stem cells. To investigate this, xenograft tumors from mice treated with VLS control peptide, SLV Fap1-blocking peptide, or oxaliplatin with VLS or SLV peptide were analyzed for co-localization of CD133 and phospho-Fas or phosphoGsk $3 \beta$. We found phosphorylation of Fas (Figure 7A) or Gsk $3 \beta$ (Figure 7B) in viable CD133 ${ }^{+}$tumor cells from mice treated with SLV peptide, which increased in mice undergoing combined treatment with oxaliplatin and SLV.

\section{DISCUSSION}

Our findings suggest Fap1 expression is a characteristic of $\mathrm{CD}_{133^{+}}$colon cancer cell stem cells. Our studies also suggest that increased Fap1 expression in metastasis versus primary tumors, or pre versus post platinum chemotherapy, is related to relative abundance of these cells in the tumor. In SW480/SW620 CD133+ colon cancer cells, we identified an association between increased Fap 1 and decreased sensitivity to either Fas or oxaliplatin induced apoptosis. And, Fap1 inhibition increased Fas-induced apoptosis and re-sensitized these cells to oxaliplatin in vitro. In a murine xenograft model, Fap1 inhibition was associated with decreased
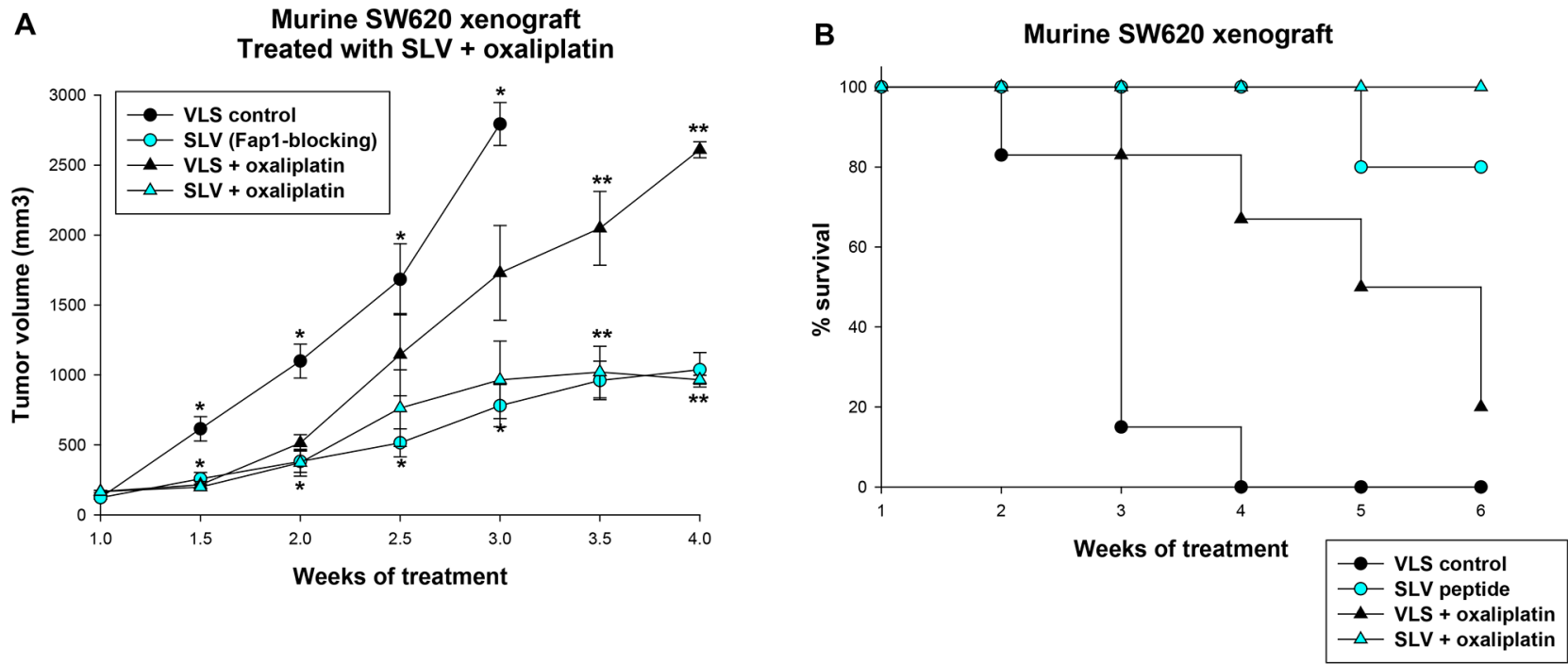

Figure 4: Fap1-inhibition decreases tumor growth in a murine xenograft model of colon cancer. SW620 cells were injected in the flanks of athymic Nude mice and tumor volume was determined biweekly. Some mice were injected daily with Fap1-blocking SLV peptide and others with VLS control peptide ( $\mathrm{n}=12$ per cohort). Other mice were treated weekly with oxaliplatin (day 0,7 and 14$)$ and daily with Fap1 blocking SLV peptide or VLS control peptide ( $\mathrm{n}=12$ per cohort). (A) Treatment with SLV peptide decreases the rate of tumor growth with or without oxaliplatin. Significant differences in tumor size at the same time point are indicated by ${ }^{*}$ or ${ }^{* *}(\mathrm{p}<0.01, \mathrm{n}=12)$. $(\mathbf{B})$ Treatment with oxaliplatin or SLV peptide increases survival, and the combination increases survival more than either alone. The percent of surviving mice during SLV versus VLS peptide treatment over time was determined $\left(X^{2}=5.52, p=0.02, n=12\right.$ for comparison of mice treated with VLS vs SLV peptide, and $\mathrm{X}^{2}=6.2, \mathrm{p}=0.01, \mathrm{n}=12$ for comparison of mice treated with oxaliplatin with VLS versus SLV peptide). 
tumor growth, delayed progression after oxaliplatin, decreased relative abundance of $\mathrm{CD} 133^{+} \mathrm{CD} 44^{+}$cells, and phosphorylation of Fap1 substrates (Fas and Gsk3 $\beta$ ).

These studies also suggest Fap1 or related substrates might be rationale therapeutic targets to decrease metastasis and delay disease progression in colon cancer. Cancer stem cell-targeting is essential to cure any malignancy, and Fap1 is a potential target in these cells. Although prior studies of Fap1 investigated effects on cisplatin responsiveness in vitro, we chose to study oxaliplatin in vivo because it is the key agent in contemporary colon cancer treatments [27]. Differences between cisplatin and oxaliplatin for their effects in colon cancer that are not well defined at the mechanistic level [28]. We plan to use in vivo models from our studies to investigate this in detail for Fap1 regulated events.

Although CRC-CSCs are $\mathrm{CD} 133^{+}$, additional markers may be associated with functional activities of interest. Future studies in the laboratory will clarify if additional subpopulations of Fap1-overexpressing CSCs are specifically involved in relapse after oxaliplatin treatment or in metastasis.
Fap1-substrates of unknown significance for colon cancer pathogenesis include I $\mathrm{bb} \alpha$ (an inhibitor of Nfkb) and PDZ-Rho-GEF (a Rho activator) [29, 30]. These proteins will be the topic of future studies. It is also possible SLV peptide influences other proteins with PDZ-type protein interaction domains. Candidates would include Taz (involved in mesenchymal differentiation) or Dishevelled 1 (Dv11; modular of Wnt activity) [31, 32]. These proteins will also be investigated in future studies. However, our current studies identified increased phosphorylation of Fas and Gsk $3 \beta$ in xenograft tumors from SLV peptide treated mice compared to mice treated with control peptide. This would not be anticipated with inhibition of Dvll or Taz.

We found Irf2 repressed PTPN13 transcription in SW620 colon cancer cells. Inflammatory mediators, including Ifn $\gamma$ and Tnf $\alpha$, influence Irf 2 expression and activity in a variety of cell types, resulting in termination of the inflammatory response [33]. In future studies, we plan to investigate the impact of inflammatory mediators on Fap1 expression and Fas sensitivity in $\mathrm{CD} 133^{+}$versus CD133- colon cancer cells.
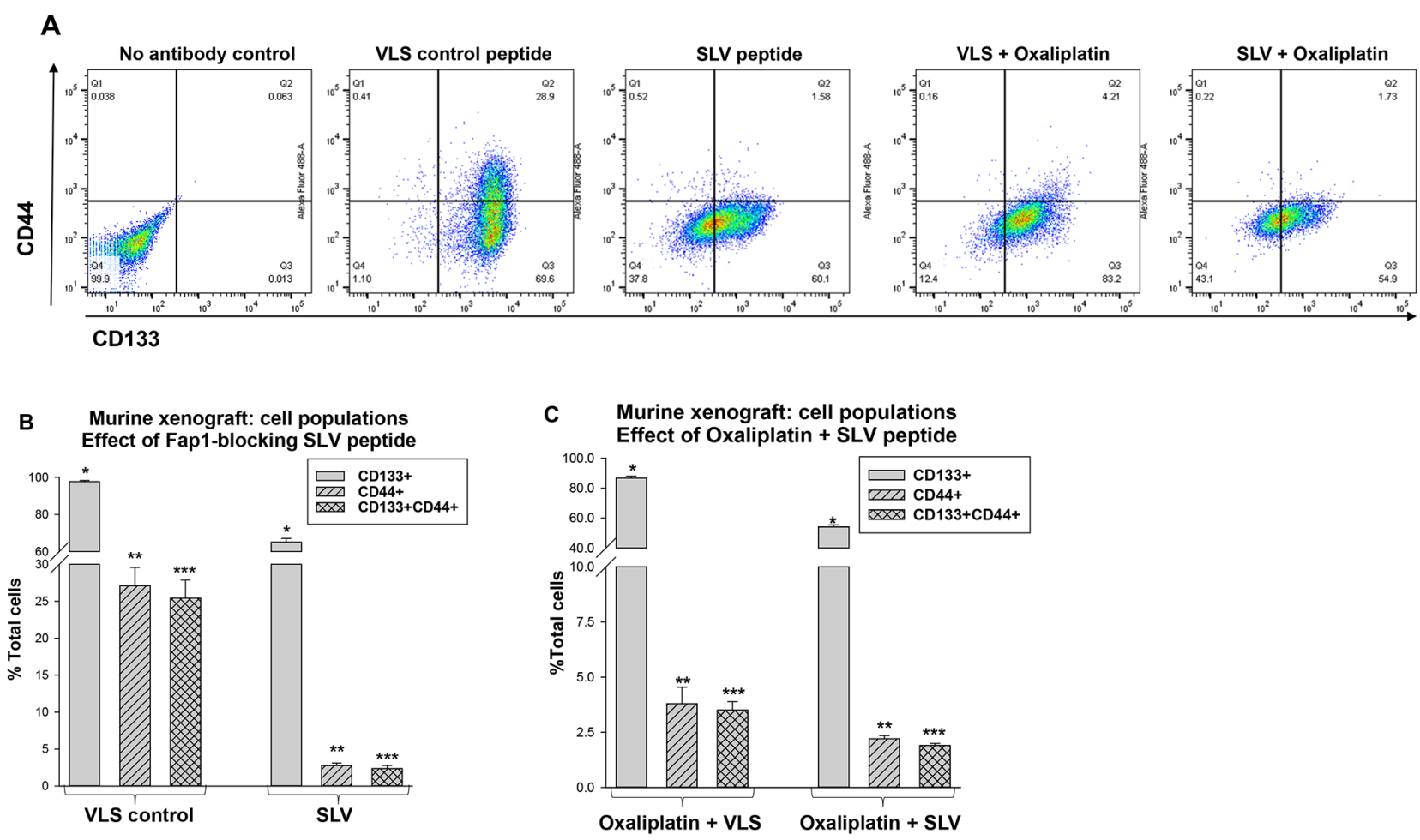

Figure 5: Fap1-inhibition decreases abundance of $\mathrm{CD} 133^{+} \mathrm{CD} 44^{+}$cells in in a murine xenograft model of colon cancer with or without oxaliplatin. Tumors from the mice described above were analyzed for cell population distribution after various treatments. (A) Histograms from flow cytometry demonstrate decreased abundance of CD $133^{+} \mathrm{CD} 44^{+}$cells after treatment with SLV peptide with or without oxaliplatin. A representative histograms for each cohort is shown. (B) Treatment with SLV peptide decreases relative abundance of $\mathrm{CD} 133^{+} \mathrm{CD} 44^{+}$cells in xenograft tumors. Tumors were simultaneously harvested from mice treated with SLV peptide versus VLS control (when control group tumors were $>2,000 \mathrm{~mm}^{3}$ ) and analyzed for CD133 and CD44 expression by flow cytometry. Significant differences indicated by ${ }^{*},{ }^{* *}$, or ${ }^{* * *}$. $(\mathrm{p}<0.001, \mathrm{n}=6)$. (C) The addition of SLV peptide to oxaliplatin treatment decreases relative abundance of $\mathrm{CD} 133^{+} \mathrm{CD}_{4}{ }^{+}$cells in xenograft tumors. Tumors were simultaneously harvested from mice treated with oxaliplatin + SLV peptide versus VLS control (when control group tumors were $>2,000 \mathrm{~mm}^{3}$ ) and analyzed for CD133 and CD44 expression by flow cytometry. Significant differences indicated by ${ }^{*},{ }^{* *}$, or ${ }^{* * *}$. $(\mathrm{p}<0.001, \mathrm{n}=6)$. 
Our studies suggest that Fap1-inhibition after oxaliplatin chemotherapy might be a rational approach to colon cancer. Maintenance therapy is unusual in solid tumors, but is has an increasing role with current immunotherapeutic approaches [27]. Similarly, we previously found that the addition of SLV peptide to tyrosine kinase inhibitor (TKI) prevented emergence of TKI resistance or blast crisis in a murine CML model; events observed with TKI alone [20].

These studies suggest Fap1 may be a tissue agnostic target for malignant stem cells in diseases as diverse as
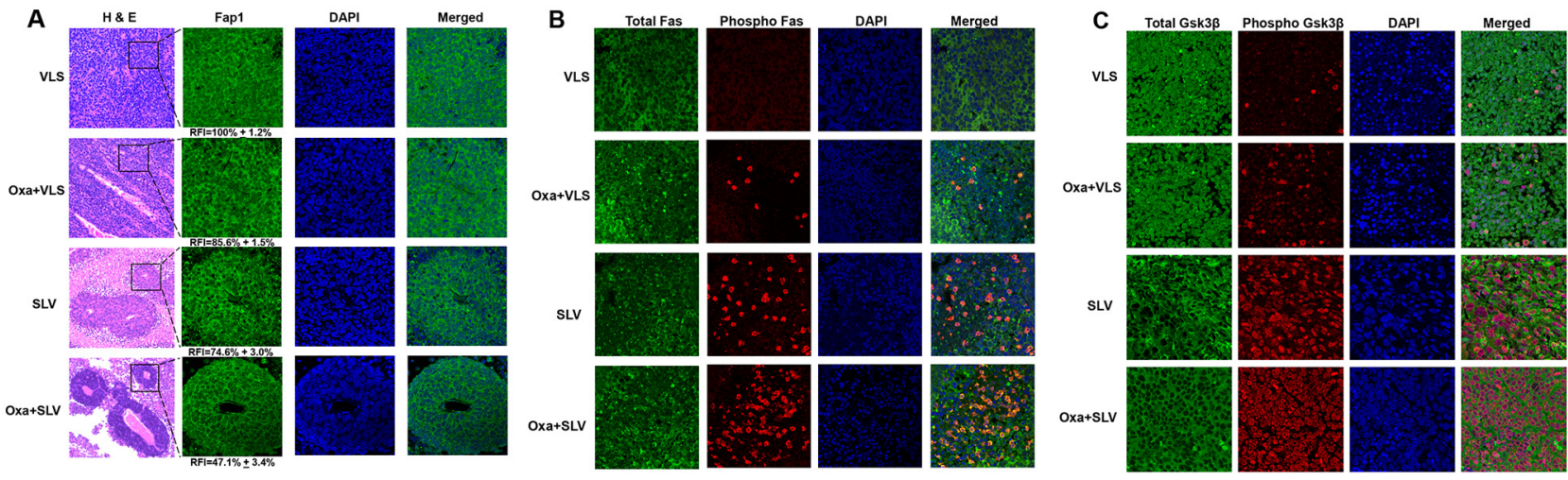

Figure 6: Fap1-inhibition with SLV peptide increases phosphorylation of Fap1-substrates Fas and Gsk3ß in a murine xenograft model. SW620 cells were injected in the flanks of athymic Nude mice and tumor volume was determination biweekly. Mice were treated weekly with oxaliplatin (days 0, 7 and 14) and injected daily with Fap1 blocking SLV peptide or VLS control peptide, or treated with SLV or VLS peptide alone ( $n=12$ per cohort). Tumors were simultaneously harvested from cohorts of mice when control tumors were $>2,000 \mathrm{~mm} 3$. (A) SLV peptide increases gland formation in xenograft tumors with or without oxaliplatin. Histology was analyzed by hematoxylin/ eosin staining. Fap1 expression was determined by immunofluorescence. Relative fluorescent intensity (RFI) of Fap1 staining is indicated below relevant panels. (B) SLV peptide increases Fas-phosphorylation in xenograft tumors with or without by oxaliplatin. Immunofluorescent detection of total versus phospho-Fas was performed with DAPI staining of nuclei. Areas without gland formation were selected for this study. (C) SLV peptide increases Gsk3 $\beta$-phosphorylation with or without oxaliplatin. Immunofluorescent detection of total versus phospho- Gsk $3 \beta$ was performed with DAPI staining of nuclei. Areas without gland formation were selected for this study.
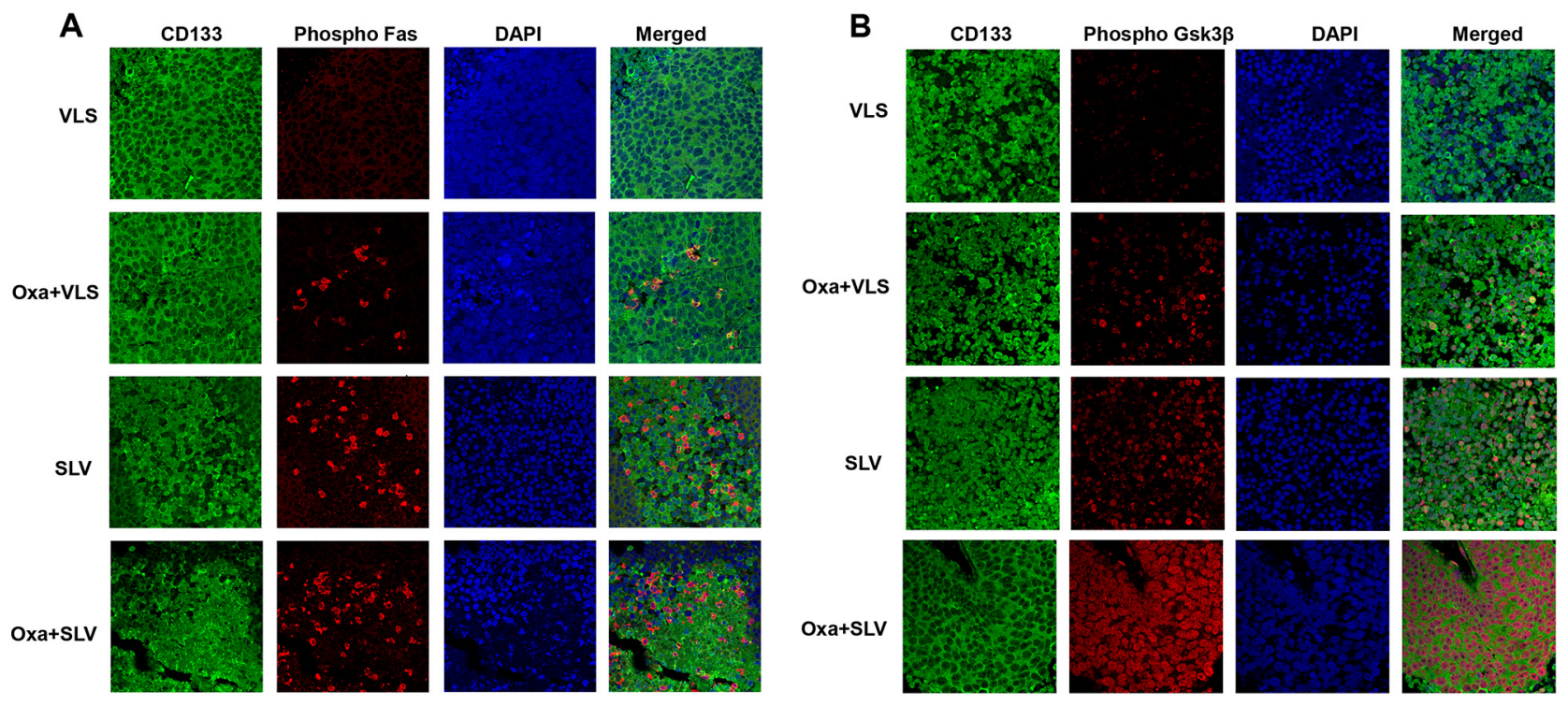

Figure 7: Fap1-inhibition with SLV peptide increases Fas and Gsk3 $\beta$ phosphorylation in CD133 ${ }^{+}$cells in a murine xenograft model. SW620 cells were injected in the flanks of athymic Nude mice and tumor volume was determination biweekly. Mice were treated weekly with oxaliplatin (days 0,7 and 14) and injected daily with Fap1 blocking SLV peptide or VLS control peptide, or treated with SLV or VLS peptide alone ( $\mathrm{n}=12$ per cohort). Tumors were simultaneously harvested from cohorts of mice when control tumors were $>2,000 \mathrm{~mm} 3$. (A) SLV peptide increases Fas phosphorylation in $\mathrm{CD} 133^{+}$xenograft tumors with or without oxaliplatin. Immunofluorescent detection of phospho-Fas or CD133 was performed with DAPI staining of nuclei. (B) SLV peptide increases Gsk3 $\beta$ phosphorylation in $\mathrm{CD}_{133^{+}}$xenograft tumors with or without oxaliplatin. Immunofluorescent detection of phospho-Gsk3 $\beta$ or CD133 was performed with DAPI staining of nuclei. 
colon cancer and CML. Normal stem cells that reside in colon crypts or the bone marrow niche balance selfrenewal with differentiation to replace mature cells lost to programmed cell death on an ongoing basis. This process may require common regulatory mechanisms that are susceptible to derangement during transformation in both malignancies. Fap1 is also increased in head/neck cancer and glioblastoma, and these diseases may be of additional interest to better understand the role of Fap1 in stem cell biology and therapeutic targeting.

\section{MATERIALS AND METHODS}

\section{Plasmids}

PTPN13 promoter sequences were amplified from the U937 cell line and reporter plasmids generated in pGL3-basic or pGL3-promoter vectors (Promega, Madison, WI), as described [21]. The cDNA for human Irf2 cDNA was obtained from Dr. Gary S. Stein (University of Massachusetts Medical School, Worcester, MA) and for Icsbp from Dr. Ben Zion-Levi (Technion, Haifa, Israel). Expression plasmids for Icsbp or Irf2, or shRNAs specific to Icsbp or Irf2 (or scrambled control shRNA) were previously described $[21,34]$.

\section{Cell lines}

Colon cancer cell lines SW480 and SW620 were obtained from the American Type Culture Collection (ATCC, Manassas, VA) [24]. Cells were cultured in DME, $10 \%$ fetal bovine serum and $1 \%$ penicillin/streptomycin solution and authenticated annually by STR analysis according to manufacturer's instructions (GenePrint 10 system; Promega, Madison, WI).

\section{Quantitative real time PCR}

Cells were lysed in Trazol for RNA isolation by standard techniques [21]. Oligonucleotide primers were synthesized by MWG Biotech (Piedmont, NC). Real time PCR was performed on an Applied Biosystems machine by the SYBR green/standard curve method. Six independent samples were assayed in triplicate for each experiment and results were normalized to $18 \mathrm{~S}$. A normal distribution was found for biological replicates.

\section{Reporter gene assays}

SW620 cells $\left(3 \times 10^{7}\right)$ were transfected by electroporation with reporter constructs (with firefly luciferase reporter, $20 \mu \mathrm{g}$ ) containing the PTPN13 promoter (in pGL3-basic) or PTPN13 cis element (in pGL3-promoter) with an internal control for transfection efficiency (TK-renilla luciferase, $2 \mu \mathrm{g}$ ). Some cells were transfected with vectors to overexpress or Icsbp or Irf2 (vs empty vector control; $5 \mu \mathrm{g}$ of vector). Other cells were transfected with vectors to express shRNAs specific to Icsbp or Irf2 (or scrambled shRNA control vector; 5 $\mu \mathrm{g})$. Luciferase activity was analyzed in triplicate for six independent experiments and normal distribution of values was observed for biological replicates.

\section{Flow cytometry}

Adherent cells were detached with $0.05 \%$ Trypsin (Corning, Manassas, VA), washed and re-suspended in phosphate buffered saline (PBS). Tumors were mechanically and enzymatically disaggregated into singlecell suspensions, as in [35]. $1 \times 10^{6}$ cells were incubated with PE-conjugated anti-CD133 and/or FITC-conjugated anti-CD44 (eBioscience, San Diego, CA; 12-1338-42 and 11-0441-82). Labeled cells were analyzed by LSR Fortessa Cell Analyzer (BD Bioscience). Data was analyzed with Flowjo software. At least three samples were analyzed in triplicate and a normal distribution was observed for biological replicates.

\section{Affinity purification of $\mathrm{CD} 133^{+}$cells}

Cells were incubated with magnetic bead-conjugated anti-CD133 antibody and separated in a magnetic column, per manufacturer's instructions (Miltenyi Biotech, Auburn, CA; 130-097-049).

\section{Western blots}

For Western blots of total lysate proteins, cells were lysed in RIPA buffer, and proteins were separated by SDS-PAGE and transferred to nitrocellulose. Membranes were serially probed with antibodies to Fap1 (Invitrogen, Carlsbad, CA; PA5-50660) and Tubulin (as a loading control). In other experiments, plasma membrane proteins were extracted (Abcam, Cambridge, MA; Ab65400) and Western blots performed, as described above. Membranes were serially probed with antibodies to Fas (Abcam; Ab110021) and $\mathrm{Na}^{+} / \mathrm{K}^{+}$ATPase (as a loading control; Ab76020).

\section{Apoptosis assays}

Some cells were labeled with anti-human FITC conjugated antibodies to CD133 (eBioscience, San Diego, CA), and others were separated with CD133 MicroBead Kit (Miltenyi Biotec, Auburn, CA). Apoptosis was assessed by flow cytometry using an Annexin V-APC Apoptosis Detection Kit according to manufacturer's instructions (eBioscience, San Diego, CA; 88-8007-74). In some experiments, apoptosis was induced with Fas-agonist antibody (monoclonal antibody clone CH-11, Millipore, Milwaukee, WI). Four independent experiments were performed in triplicate. Biological replicates were observed to have a normal distribution. 


\section{Immunohistochemistry}

Tumors were fixed in $4.0 \%$ paraformaldehyde, paraffin-embedded and sectioned. Slides were blocked after deparaffinization, rehydration and antigen retrieval; incubated with primary and secondary antibodies; and nuclei fluorescently stained with 4',6-diamidino-2phenylindole (DAPI) (Life Technologies, USA). Images were obtained with a Nikon A1R (20x). Antibodies include: anti-Fap1 or anti-Fas (Abcam, Cambridge, MA; ab198882, ab110021); anti-phospho Fas or anti-phospho Gsk3 beta (Thermo Fisher, Rockford, IL; PAS-38490, 702230); anti-Gsk3 $\beta$ (Novus, Littleton, CO; NBP147470); Cy3 AffiniPure Donkey Anti-Rabbit IgG, Cy2 AffiniPure Donkey Anti-Goat IgG, or Cy2 AffiniPure Donkey Anti-Mouse IgG (Jackson ImmunoResearch Laboratories, West Grove, PA; 711-165-152, 705-225$147,715-225-150)$.

\section{Murine xenograft}

Washed SW620 cells were re-suspended in a 50:50 mix of sterile PBS and matrigel $\left(2.0 \times 10^{7}\right.$ per $\left.\mathrm{ml}\right)$. Cell suspensions $(0.1 \mathrm{ml})$ were injected in the right flank of athymic Nude mice (14-15 weeks old). Once tumors were $150-200 \mathrm{~mm}^{3}$, mice were randomized to receive SLV peptide or VLS control (5 mg/kg IP in $0.2 \mathrm{ml}$ daily). Other mice were randomized to receive oxaliplatin $(10 \mathrm{mg} / \mathrm{kg})$ or saline control weekly for three weeks with concurrent SLV or VLS peptide. Investigators were not blinded in these studies. Animals were sacrificed when tumors were $>2,000 \mathrm{~mm}^{3}$. Each cohort consisted of 12 animals to permit detection of a $15 \%$ difference between groups. There was a normal distribution of tumor growth within the cohorts.

\section{Statistical analysis}

Data was analyzed by SigmaStat software. Differences of means were determined by two tailed Student's $T$ test with standard error. One way ANOVA was used to compare more than two groups. Variance of groups within experiments was determined. Survival curves were compared by LogRank analysis. Statistical significance was $\mathrm{p}<0.02$.

\section{Animal use approvals}

Studies were approved by the Northwestern University Animal Care and Use Committee.

\section{Author contributions}

WQH performed the majority of experiments, LB assisted with analysis of tumor samples, EAE designed the experiments and wrote the manuscript.

\section{ACKNOWLEDGMENTS AND FUNDING}

Murine xenografts were performed with assistance from the Developmental Therapeutics Core in the Lurie Cancer Center at Northwestern University. Work was supported by a VA Merit Review to EAE (BX002067).

\section{CONFLICTS OF INTEREST}

No authors have conflicts to report.

\section{REFERENCES}

1. https://seer.cancer.gov/report_to_nation/incidence.html.

2. Hochster HS, Grothey A, Hart L, Rowland K, Ansari R, Alberts S, Chowhan N, Ramanathan RK, Keaton M, Hainsworth JD, Childs BH. Improved time to treatment failure with an intermittent oxaliplatin strategy: results of CONcePT. Ann Oncol. 2014; 25:1172-8.

3. Hammond WA, Swaika A, Mody K. Pharmacologic resistance in colorectal cancer: a review. Ther Adv Med Oncol. 2016; 8:57-84.

4. Garza-Treviño EN, Said-Fernández SL, MartínezRodríguez HG. Understanding the colon cancer stem cells and perspectives on treatment. Cancer Cell Int. 2015; 15:2.

5. O'Brien CA, Pollett A, Gallinger S, Dick JE. A human colon cancer cell capable of initiating tumour growth in immunodeficient mice. Nature. 2007; 445:106-110.

6. Chu P, Clanton DJ, Snipas TS, Lee J, Mitchell E, Nguyen ML, Hare E, Peach RJ. Characterization of a subpopulation of colon cancer cells with stem cell-like properties. Int J Cancer. 2009; 124:1312-1321.

7. Shimokawa M, Ohta Y, Nishikori S, Matano M, Takano A, Fujii M, Date S, Sugimoto S, Kanai T, Sato T. Visualization and targeting of LGR5+ human colon cancer stem cells. Nature. 2017; 545:187-196.

8. Kozovska Z, Gabrisova V, Kucerova L. Colon cancer: cancer stem cells markers, drug resistance and treatment. Biomed Pharmacother. 2014; 68:911-6.

9. Grunt TW, Hebar A, Laffer S, Wagner R, Peter B, Herrmann H, Graf A, Bilban M, Posch M, Hoermann G, Mayerhofer M, Eisenwort G, Zielinski CC, et al. Prominin-1 (CD133, AC133) and dipeptidyl-peptidase IV (CD26) are indicators of infinitive growth in colon cancer cells. Am J Cancer Res. 2015; 5:560-74.

10. Senbanjo LT, Chellaiah MA. CD44: a multifunctional cell surface adhesion receptor is a regulator of progression and metastasis of cancer cells. Front Cell Dev Biol. 2017; 5:18.

11. Shmelkov SV, Butler JM, Hooper AT, Hormigo A, Kushner J, Milde T, St Clair R, Baljevic M, White I, Jin DK, Chadburn A, Murphy AJ, Valenzuela DM, et al. CD133 expression is not restricted to stem cells, and both CD133+ and CD133- metastatic colon cancer cells initiate tumors. J Clin Invest. 2008; 118:2111-20. 
12. Saras J, Claesson-Welsh L, Heldin CH, Gonex LJ. Cloning and characterization of PTPL1, a protein tyrosine phosphatase with similarities to cytoskeletal-associated proteins. J Biol Chem. 1994; 269:24082-24089.

13. Oncomine, Research Addition, University of Michigan, Ann Arbor (www.oncomine.org).

14. Yanagisawa J, Takahashi M, Kanki H, Sawa E, Nishitoba T, Kamishohara M, Kobayshi E, Kataoka S, Sato Y. The molecular interaction of Fas and Fap1. J Biol Chem. 1997; 272:8539-8545.

15. Huang W, Bei L, Eklund EA. Fas-associated phosphatase 1 (Fap1) influences $\beta$ catenin activity in myeloid progenitor cells expressing the Bcr-abl oncogene. J Biol Chem. 2013; 2288:12766-76.

16. Xiao ZY, Wu W, Eagleton N, Chen HQ, Shao J, Teng H, Liu TH, Jiang ZM, Yao HR. Silencing Fas-associated phosphatase 1 expression enhances efficiency of chemotherapy for colon carcinoma with oxaliplatin. World J Gastroenterol. 2010; 16:112-8.

17. Yao H, Song E, Chen J, Hamar P. Expression of Fap1 by human colon adenocarcinoma: implication for resistance against Fas-mediated apoptosis in cancer. $\mathrm{Br} \mathrm{J}$ Cancer. 2004; 91:1718-25.

18. Kozlov G, Gehring K, Ekiel I. Solution structure of the PDZ2 domain from human phosphatase hPTP1E and its interactions with c-terminal peptides from the Fas receptor. Biochemistry. 2000; 39:2572-80.

19. Kozlov G, Banville D, Gehring K, Ekiel I. Solution structure of the PDZ2 domain from cytosolic human phosphatase hPTP1E complexed with a peptide reveals contribution of the B2-B3 loop to PDZ-domain-ligand interactions. J Mol Biol. 2002; 320:813-20.

20. Huang W, Luan CH, Hjort EE, Bei L, Mishra R, Sakamoto KM, Platanias LC, Eklund EA. The role of Fas-associated phosphatase 1 in leukemia stem cell persistence during tyrosine kinase inhibitor treatment of chronic myeloid leukemia. Leukemia. 2016; 30:1502-9.

21. Huang W, Zhu CL, Wang H, Horvath E, Eklund EA. ICSBP/ IRF8 represses PTPN13 gene transcription in differentiating myeloid cells. J Biol Chem. 2008; 283:7921-35.

22. Slattery ML, Lundgreen A, Bondurant KL, Wolff RK. Interferon-signaling pathway: associations with colon and rectal cancer risk and subsequent survival. Carcinogenesis. 2011; 32:1660-7.

23. Tillman DM, Harwood FG, Gibson AA, Houghton JA. Expression of genes that regulate Fas signalling and apoptosis in colon carcinoma cells. Cell Death Differ. 1998; 5:450-7.
24. Leibovitz A, Stinson JC, McCombs WB, McCoy CE, Mazur KD, Mabry MD. Classification of human colorectal adenocarcinoma cell lines. Cancer Res. 1976; 36:4562-4569.

25. Driggers PH, Ennist DL, Gleason SL, Mak WH, Marks MS, Levi BZ, Flanagan JR, Appella E, Ozato K. An interferon gamma-regulated protein that binds the interferon-inducible enhancer element of major histocompatibility complex class I genes. Proc Natl Acad Sci U S A. 1990; 87:3743-7.

26. Harada H, Fujita T, Miyamoto M, Kimura Y, Maruyama M, Furia A, Miyata T, Taniguchi T. Structurally similar but functionally distinct factors, IRF-1 and IRF-2, bind to the same regulatory elements of IFN and IFN-inducible genes. Cell. 1989; 58:729-39.

27. National Comprehensive Cancer Network (www.ncen.org).

28. Virag P, Perde-Schrepler M, Fischer-Fodor E, Tatomir C, Dorneanu SA, Cernea VI, Irimie A. Superior cytotoxicity and DNA cross-link induction by oxaliplatin versus cisplatin at lower cellular uptake in colorectal cancer cell lines. Anticancer Drugs. 2012; 23:1032-8.

29. Nakai Y, Irie S, Sato TA. Identification of $\mathrm{IKB} \alpha$ as a substrate of Fas-associated phosphatase-1. Eur J Biochem. 2000; 267:7170-5.

30. Saras J, Franzén P, Aspenström P, Hellman U, Gonez LJ, Heldin CH. A novel GTPase-activating protein for Rho interacts with a PDZ domain of the protein-tyrosine phosphatase PTPL1. J Biol Chem. 1997; 272:24333-8.

31. Lei QY, Zhang H, Zhao B, Zha ZY, Bai F, Pei XH, Zhao $\mathrm{S}$, Xiong Y, Guan KL. TAZ promotes cell proliferation and epithelial-mesenchymal transition and is inhibited by the hippo pathway. Mol Cell Biol. 2008; 28:2426-36.

32. Lee JS, Ishimoto A, Yanagawa S. Characterization of mouse dishevelled (Dvl) proteins in Wnt/Wingless signaling pathway. J Biol Chem. 1999; 274:21464-70.

33. Harada H, Taniguchi T, Tanaka N. The role of interferon regulatory factors in the interferon system and cell growth control. Biochimie. 1998; 80:641-50.

34. Huang W, Zhou W, Saberwal G, Konieczna I, Horvath E, Katsoulidis E, Platanias LC, Eklund EA. Interferon consensus sequence binding protein (ICSBP) decreases beta-catenin activity in myeloid cells by repressing GAS2 transcription. Mol Cell Biol. 2010; 30:4575-94.

35. Dalerba P, Dylla SJ, Park IK, Liu R, Wang X, Cho RW, Hoey T, Gurney A, Huang EH, Simeone DM, Shelton AA, Parmiani G, Castelli C, Clarke MF. Phenotypic characterization of human colorectal cancer stem cells. Proc Natl Acad Sci U S A. 2007; 104:10158-63. 